\title{
A geopolítica do futebol em transformação: o caso chinês
}

\author{
The Geopolitics of Football in Transformation: the Chinese Case
}

\author{
Carlos Rodrigues \\ Universidade de Aveiro, Aveiro/Portugal \\ Doutor em Ciências Sociais, Universidade de Aveiro \\ cjose@ua.pt \\ Emanuel Leite Jr. \\ Universidade de Aveiro, Aveiro/Portugal \\ Doutorando em Políticas Públicas, Universidade de Aveiro
}

\begin{abstract}
Resumo: A China só esteve em uma Copa do Mundo de futebol masculino. Foi em 2002 e sua seleção perdeu os três jogos que disputou. Na 75a posição no ranking da FIFA (junho 2018), a seleção chinesa não se classificou para a Copa do Mundo 2018. As autoridades chinesas, entretanto, querem mudar essa realidade. Para isso, em 2016 foi lançado o "Plano de desenvolvimento do futebol a médio e longo prazo (2016-2050)". Dentre os objetivos, está o de sediar uma Copa. A meta final é ainda mais ambiciosa: fazer da China uma potência mundial. Para tal, o governo conta com o apoio da iniciativa privada. E desde o lançamento do 'Plano', os investimentos de empresas chinesas no futebol aumentaram significativamente, assim como na Copa da Rússia, em que marcas chinesas representaram 37\% dos patrocinadores da competição. Este artigo objetiva analisar de que forma o 'Plano', como instrumento de Soft Power chinês, tem contribuído para mudar a geopolítica do futebol.
\end{abstract}

Palavras-Chave: Futebol; China; Copa do Mundo; Soft Power; Geopolítica.

ABSTRACT: China has been only once to a men's World Cup. It was in 2002 and the Chinese team lost all three games they played. Currently in the $75^{\text {th }}$ place in FIFA's ranking, the Chinese team did not qualify for the 2018 World Cup. Chinese authorities, however, want to change this scenario. In 2016 the Chinese government launched the "Medium and long-term football development plan (2016-2050)". One of the goals is to host a World Cup. The ultimate goal is even more ambitious: China wants to become a world football power. To this end, the government expects the support of the private sector. And since the launch of the 'Plan', investments by Chinese companies in football have increased significantly. As in the World Cup in Russia, in which Chinese brands held 37\% of the sponsorship deals of the competition. This paper aims to analyze how the 'Plan', as a Chinese's Soft Power tool, has been contributing to change the geopolitics of football.

KeYwoRDS: Football; China; World Cup; Soft Power; Geopolitics. 


\section{INTRODUÇÃO}

Embora tenha sido o primeiro esporte profissionalizado na China, ${ }^{1}$ na esteira da reforma econômica pelo qual o país passou no início dos anos 1990 - "socialismo de mercado" -, ${ }^{2}$ o futebol masculino chinês segue sendo uma decepção e por vezes motivo de vexame, como na derrota por 5 a 1 para a Tailândia, em seu próprio território, em $2013 .^{3}$

Ocupando a 75a posição no ranking da Federação Internacional de Futebol (FIFA) (FIFA, 2018), a seleção chinesa não esteve presente na última edição da Copa do Mundo, disputada entre junho e julho de 2018, na Rússia. Até hoje, os chineses só participaram da Copa do Mundo uma vez. Foi em 2002, no Mundial disputado na Coreia do Sul e no Japão. Com três derrotas em três jogos, nove gols sofridos e nenhum marcado, a China se despediu cedo e de forma inglória do evento.

Os fracassos da seleção mostram como o futebol ainda não foi capaz de replicar o sucesso da estratégia olímpica do país, implementada nos anos $1980^{4}$ e aprofundada nos anos 1990 e 2000, através do 'Juguo Tizhi' (举国体制), em mandarim, que em português significa 'todo o país apoia o esporte de alta competição'. Este sistema canalizou o máximo de recursos possível para os esportes Olímpicos ${ }^{5}$ e seu ápice ocorreu nos Jogos de Pequim, em 2008, quando a China conquistou 51 medalhas de ouro, contra 36 dos Estados Unidos.

Em 2009, Xi Jinping, na altura ainda vice-presidente, expressou o empenho do Estado chinês em desenvolver o futebol. ${ }^{6}$ Agora presidente, e fã de futebol, Xi já admitiu ter "três sonhos da Copa do Mundo": participar da Copa; sediar a Copa e

\footnotetext{
${ }_{1}^{1}$ HONG; ZHOUXIANG. The Professionalisation and Commercialisation of Football in China (1993-2013), 2013. ${ }^{2}$ CHEN et al. Who Provides the Capital for Chinese Growth: the Public or the Private Sector?, 2017; GONG; CORTESE. A Socialist Market Economy with Chinese Characteristics: The Accounting Annual Report of China Mobile, 2017.

${ }^{3}$ GIULIANOTTI. The Beijing 2008 Olympics: Examining the Interrelations of China, Globalization, and Soft Power. 2015; HONG; ZHOUXIANG. The Professionalisation and Commercialisation of Football in China (1993-2013), 2013; TAN et al. Xi Jin-Ping's World Cup Dreams: From a Major Sports Country to a World Sports Power, 2016.

${ }^{4}$ HONG; ZHOUXIANG. Sports and Politics in the 1980s: The Olympic Strategy, 2012a.

${ }^{5}$ HONG; ZHOUXIANG. From Barcelona to Athens (1992-2004): "Juguo Tizhi" and China's quest for global power and Olympic glory, 2012b.

${ }^{6}$ TAN et al. Xi Jin-Ping's World Cup Dreams: From a Major Sports Country to a World Sports Power, p. 8.
} 
ser campeão do mundo de futebol.7 Já em 2015, foi lançado o "Plano geral de reforma para impulsionar o desenvolvimento do futebol na China" (中国足球改革发展总体方案), seguido pelo documento principal, em 2016: o “Plano de desenvolvimento do futebol a médio e longo prazo (2016-2050)" (中国足球中长期发展规划 [2016-2050年]). Um plano ambicioso, que pretende fazer da China uma potência do futebol mundial.

Contudo, podem se associar objetivos que vão para além dos "três sonhos da Copa" de seu presidente que a China tenha lançado este plano. Isso porque a estratégia busca fazer do futebol a mola propulsora para o desenvolvimento da indústria esportiva. Esta é uma das metas do governo Xi. Em 2014, o Conselho de Estado publicou as “Opiniões para a aceleração do desenvolvimento da indústria desportiva e promover o consumo do esporte” (国务院䏌于加快发展体育产业促进体育消费的若干意见): marco para a decolagem da indústria esportiva chinesa, ${ }^{8}$ estipulando que em 2025 este setor fature US\$ 813 bilhões. ${ }^{9}$ A título comparativo, de acordo com a Plunkett Research, a indústria esportiva mundial movimentou cerca de US\$1,5 trilhão em 2015, US\$ 498,4 bilhões apenas nos Estados Unidos. ${ }^{10}$

Para cumprir estes objetivos, o Estado conta com a participação da iniciativa privada. 0 governo deixa de intervir diretamente no mercado, passando apenas a guiar e apoiar o desenvolvimento da indústria, podendo, ainda, participar em conjunto na promoção da indústria. ${ }^{11}$

E a iniciativa privada tem respondido às expectativas. Por isso, a ausência da seleção chinesa nos gramados russos não significou que a China tenha ficado de fora da Copa do Mundo 2018. 0 escândalo de corrupção que abalou a FIFA em 2015 fez com que muitas multinacionais rescindissem seus contratos de patrocínio. Empresas chinesas preencheram este vácuo e se tornaram parceiras da FIFA e de suas competições. Na Copa da Rússia, a China se fez presente através das

\footnotetext{
7 TAN et al. Xi Jin-Ping's World Cup Dreams: From a Major Sports Country to a World Sports Power, p. 9.

${ }^{8}$ LIU. The Sports Industry: the Next Big Thing in China?, 2017.

${ }^{9}$ NIELSEN SPORTS. 2016.

10 PLUNKETT RESEARCH. 2016.

${ }^{11}$ ZHAN. The History and Development Trend of China's Sports Industry Policy, 2013.
} 
empresas Wanda, Hisense, Vivo, Mengniu, Yadea, Luci e Diking. Sete das 19 patrocinadoras do torneio (37\%) foram chinesas. ${ }^{12}$

A partir de revisão bibliográfica e da análise de documentos políticos, 0 presente trabalho pretende analisar como o "Plano do futebol" chinês tem contribuído para projetar o status e influência do país na comunidade internacional, servindo de instrumento de atração diplomática e comercial - Soft Power -: "um país pode obter os resultados que deseja na política internacional porque outros países - admirando seus valores, emulando seu exemplo e aspirando ao seu nível de prosperidade - vão querer segui-lo". ${ }^{13}$ Ao mesmo tempo em que tenta compreender como com o dinheiro e patrocínios que traz para o jogo e sua imensa legião de fãs, ${ }^{14}$ a China tem influenciado na transformação da estrutura hierárquica da geopolítica esportiva como instrumento para se firmar como potência na arena internacional ${ }^{15}$ e também para realizar, pelo menos, o desejo de sediar a Copa do Mundo.

\section{O PLANO DE DESENVOLVIMENTO DO FUTEBOL CHINÊS}

Lançado em abril de 2016, o "Plano de desenvolvimento do futebol a médio e longo prazo (2016-2050)”（中国足球中长期发展规划 [2016-2050年]） apresenta uma estratégia de política pública formulada e implementada pelo governo Chinês, sob a tutela do Gabinete do Conselho de Estado da Conferência Conjunta Interministerial sobre Reforma e Desenvolvimento do Futebol. Este órgão reúne, dentre outros, 11 Ministérios, quatro Comissões de Conselho de Estado, cinco agências governamentais, além do Departamento de Propaganda do Partido Comunista Chinês.

A abrangência do "Plano de desenvolvimento do futebol" vai desde o sistema educacional (aumento da carga horária de educação física nas escolas, com

\footnotetext{
${ }^{12}$ KPMG. High stakes: The sponsorship and broadcasting value of the FIFA World Cup, 2018.

${ }^{13}$ NYE. Soft Power: The Means to Success in World Politics, 2004.

${ }^{14}$ GUPTA. India and the IPL: Cricket's Globalized Empire, 2009a.

${ }^{15}$ ALMEIDA; MARCHI JÚNIOR; PIKE. The 2016 Olympic and Paralympic Games and Brazil's Soft Power, 2013; CORNELISSEN. The Geopolitics of Global Aspiration: Sport Mega-Events and Emerging Powers, 2010; GRIX; LEE. Soft Power, Sports Mega-Events and Emerging States: The Lure of the Politics of Attraction, 2013.
} 
ênfase no futebol), passando pelo estímulo à prática do futebol como questão de saúde pública (visando o bem-estar físico e mental dos jovens, bem como o fortalecimento do condicionamento físico das massas), a promoção de intercâmbio cultural e diplomático com outras nações, até o objetivo de fazer do futebol a mola propulsora do desenvolvimento de toda a indústria desportiva do país, para que esta se torne um setor relevante na economia nacional, ajudando a que o país continue a crescer e prosperar. Além, claro, da principal ambição de todas que é ver a China se tornar uma potência do futebol mundial. ${ }^{16}$

O plano do futebol, originalmente, estabelecia-se em três etapas:

(i) Até 2020: 20 mil escolas especializadas em futebol, 70 mil campos de futebol, entre 30 a 50 milhões de estudantes do ensino básico e secundário praticando o desporto;

(ii) Até 2030: 50 mil escolas especializadas em futebol, a seleção chinesa masculina ser uma das melhores da Ásia, e a seleção feminina estabelecida como de "classe mundial";

(iii) Até 2050: seleção de primeiro escalão no futebol mundial (masculino), no top-20 do ranking da FIFA, tendo sediado uma Copa do Mundo e sendo uma potência mundial do futebol.

Em 2017, o Diário do Povo (人民日报), jornal oficial do Partido Comunista Chinês, publicou que as autoridades do esporte haviam alterado as metas originais. Uma mudança ainda mais ambiciosa. Ao invés de se esperar até 2030 para que existam 50 mil escolas especializadas em futebol, o objetivo é que essa marca esteja alcançada já em 2025.17

O sonho chinês e de seu presidente Xi Jinping também se inserem em estratégias geopolíticas do país, como o próprio plano atesta, ao se referir a relações diplomáticas e intercâmbios culturais. ${ }^{18} \mathrm{E}$ a experiência chinesa com os Jogos Olímpicos de Pequim em 2008 serve de parâmetro para esta investida. A China acredita que, através dos Jogos de Pequim, foi capaz de mostrar ao mundo o seu desenvolvimento e que conseguiu se colocar como uma potência mundial: econômica e esportiva. "A imagem de uma nação altamente moderna, eficiente e

\footnotetext{
${ }^{16}$ CHINA'S NATIONAL DEVELOPMENT AND REFORM COMMISSION. 2016.

${ }^{17}$ PEOPLE'S DAILY. 2017.

${ }^{18}$ CNDRC, 2016, p. 2, 10 e 16.
} 
crescentemente próspera" 19 foi o que o país tentou vender ao mundo, buscando não apenas o estabelecimento de relações diplomáticas e comerciais, como também o desenvolvimento do turismo. E esta parece ser uma das razões por trás do "plano de desenvolvimento do futebol".

Inclusive, em relação aos Jogos Olímpicos de 2008 em Pequim e o contexto geopolítico, é curioso notar que Brasil, Rússia, Índia, China e África do Sul, países emergentes, que após o crescimento econômico nos anos 2000 estabeleceram o grupo que ficou conhecido por seu acrônimo em inglês BRICS, consolidando o (re)posicionamento desses países no cenário econômico global, especialmente no que diz respeito à influência geopolítica, sediaram megaeventos esportivos.

Ou seja, o reposicionamento destes países também se verificou no contexto geopolítico desportivo. Pequim, a capital chinesa, recebeu os Jogos Olímpicos de Verão em 2008 e vai organizar os Jogos de Inverno em 2022. A Índia promoveu os Jogos da Commonwealth em 2010 (Deli). No mesmo ano, a África do Sul se tornou o primeiro país africano a sediar a Copa do Mundo FIFA. Em um período de dois anos, o Brasil teve em seu território os dois maiores megaeventos desportivos do planeta: Copa do Mundo FIFA 2014 e Jogos Olímpicos de Verão 2016 (Rio de Janeiro). A Rússia, por fim, organizou os Jogos Olímpicos de Inverno 2014 (Sochi) e vai receber a próxima edição da Copa do Mundo FIFA, em 2018.

\section{Futebol e Soft Power}

O esporte de alta competição há muito que tem sido usado tanto como uma ferramenta ideológica, quanto, como coloca Gupta, um instrumento para mostrar o seu país ao mundo. ${ }^{20}$ Por essa razão, ele tem servido aos interesses políticos, tornando-se, assim, uma importante arena para políticas públicas. ${ }^{21} \mathrm{E}$ o uso político do esporte não é uma novidade na China. Tem sido algo recorrente desde a proclamação da República Popular da China. A começar pela "sovietização do

\footnotetext{
${ }^{19}$ GIULIANOTTI. The Beijing 2008 Olympics: Examining the Interrelations of China, Globalization, and Soft Power, p. 290, tradução nossa.

${ }^{20}$ GUPTA. The Globalization of Sports, the Rise of Non-Western Nations, and the Impact on International Sporting Events, p. 1782.

${ }^{21}$ KORNEEVA; OGURTSOV. The Politicization of Sports as a Soft Power Public Resource. 2016.
} 
esporte" do país nos anos 1950 (fundamental no estabelecimento dos contatos com a União Soviética e os países do Leste Europeu); passando, no período pósrompimento das relações sino-soviéticas, pelos Jogos das Novas Forças Emergentes (GANEFO) - através do GANEFO a China visava reforçar sua liderança no Terceiro Mundo, como alternativa às potências dos Estados Unidos e União Soviética; pela "diplomacia do pingue-pongue" (que permitiu a reaproximação com os Estados Unidos em um período de tensão nas relações sino-soviéticas); até a já mencionada estratégia olímpica e a busca pela glória nos Jogos Olímpicos, ${ }^{22}$ para citar alguns exemplos.

No entendimento de Giulianotti (2015), os megaeventos esportivos, como a Copa do Mundo, "podem ser considerados uma das mais poderosas manifestações contemporâneas da globalização". Isto porque, segundo este sociólogo, estes megaeventos têm reflexos nas esferas econômica, social e política. Em termos econômicos, Giulianotti alude às cifras bilionárias envolvidas nestes torneios e a possibilidade de as cidades e países que sediam os eventos poderem "se vender". No que tange à questão social, o pesquisador recorda que estas competições são acompanhadas por bilhões de pessoas em todo o planeta. Por fim, o aspecto político, uma vez que "estes eventos atraem políticos de todo o mundo, particularmente nas cerimônias de abertura". ${ }^{23}$

Não por acaso, o presidente chinês Xi Jinping designou a Vice-Premiê Sun Chunlan como sua enviada especial para a cerimônia de abertura da Copa do Mundo da Rússia, mesmo diante da ausência de sua seleção nacional na competição. Sun, inclusive, encontrou-se com o presidente russo Vladimir Putin durante a ocasião.

Porém, foi outro encontro no mesmo evento que chamou a atenção de todo o mundo. No camarote principal do Estádio Luzhniki, em Moscou, e com o presidente da FIFA, Gianni Infantino, entre eles, Vladimir Putin e Mohammed bin Salman, o príncipe herdeiro saudita, assistiam ao jogo entre Rússia x Arábia

\footnotetext{
${ }^{22}$ HONG; ZHOUXIANG. Representing the New China and the Sovietisation of Chinese Sport (1949-1962), 2012c; HONG; ZHOUXIANG. Sport in the Great Proletarian Cultural Revolution (1966-1976), 2012d; HONG; ZHOUXIANG. China, the Asian Games and Asian Politics (1974-2006), 2012e; HONG; ZHOUXIANG. China's Sports Policy and Politics in the Post-Beijing Olympics Era, 2012f.

${ }^{23}$ GIULIANOTTI. The Beijing 2008 Olympics: Examining the Interrelations of China, Globalization, and Soft Power, p. 288, tradução nossa.
} 
Saudita juntos. Após o primeiro gol russo, os dois líderes se cumprimentaram com um simbólico aperto de mãos.

Essa cena, bem como a presença de Sun Chunlan, exemplificam porque a organização de megaeventos esportivos pode servir como instrumento de Soft Power. ${ }^{24}$

Soft Power é um conceito introduzido por Joseph Nye, que, ao descrever as relações de poder, definiu que "poder é a habilidade de influenciar as outras pessoas para se conseguir os resultados que se deseja, o que pode ser feito através da coerção, do pagamento ou da atração". 25 Em contraponto ao "poder duro", que se caracterizaria pela coerção (força militar) ou do pagamento (força econômica), haveria o Soft Power ("poder brando"). "Um país pode obter os resultados que deseja na política internacional porque outros países - admirando seus valores, emulando seu exemplo e aspirando ao seu nível de prosperidade - vai querer segui-lo". ${ }^{26}$ E na literatura alguns autores têm abordado a relação do esporte com o Soft Power. ${ }^{27}$

Voltando à mais recente edição da Copa do Mundo, verificamos como a organização do torneio foi positiva para a Rússia e seu presidente. Antes da competição, a imagem do país estava desgastada internacionalmente, associada à instabilidade, corrupção, agressividade e violência. Os comentários de quem esteve presente ao país ao longo da Copa do Mundo, entretanto, evidenciam o sucesso da estratégia de Putin, que conseguiu construir uma imagem positiva da nação que lidera. ${ }^{28}$

${ }^{24}$ GIULIANOTTI. The Beijing 2008 Olympics: Examining the Interrelations of China, Globalization, and Soft Power, 2015; KORNEEVA; OGURTSOV. The Politicization of Sports as a Soft Power Public Resource, 2016; MANGAN; OK; KWAK. East Reflects on West, East Meets West. 2013.

${ }^{25}$ NYE. China and Soft Power, 2012.

${ }^{26}$ NYE. Soft Power: The Means to Success in World Politics, 2004, tradução nossa

${ }^{27}$ BRANNAGAN; GIULIANOTTI. Soft Power and Soft Disempowerment: Qatar, Global Sport and Football's 2022 World Cup Finals, 2015; BRANNAGAN; ROOKWOOD. Sports MegaEvents, Soft Power and Soft Disempowerment: International Supporters' Perspectives on Qatar's Acquisition of the 2022 FIFA World Cup Finals, 2016; CHĀRI. Discursive Constructions of the Germany-Brazil Semi-Final Match During the Fifa 2014 World Cup, 2015; CHEN; COLAPINTO; LUO. The 2008 Beijing Olympics Opening Ceremony: Visual Insights into China's Soft Power, 2012; DELGADO. Opening Ceremonies of International Sports Events: The Other Face of Chinese Soft Power, 2016; GIULIANOTTI. The Beijing 2008 Olympics: Examining the Interrelations of China, Globalization, and Soft Power, 2015; GRIX; LEE. Soft Power, Sports MegaEvents and Emerging States: The Lure of the Politics of Attraction, 2013; KORNEEVA; OGURTSOV. The Politicization of Sports as a Soft Power Public Resource, 2016; KRZYZANIAK. The Soft Power Strategy of Soccer Sponsorships, 2016.

${ }^{28}$ ROTH. World Cup Plaudits Cheer Putin as Russia Revels in Spotlight, 2018. 
O Catar é outro bom exemplo do uso do futebol como instrumento Soft Power. Desde o dia 2 de dezembro de 2010, quando conquistou o direito de sediar a Copa do Mundo FIFA 2022, aquele emirado tem estado no centro das atenções do futebol mundial. A candidatura catari se inseriu dentro de um plano estratégico do país que tem no esporte e nos megaeventos esportivos o principal elemento para mudar sua imagem perante a opinião pública internacional. ${ }^{29}$ Segundo analistas, mais do que fazer do país uma referência esportiva, a intenção das autoridades do Qatar é dissociar a imagem do emirado da ideia de ser um Estado financiador do terrorismo. ${ }^{30}$

\section{FUTEBOL E "NATION BRANDING”}

O exercício do Soft Power no esporte não ocorre apenas na organização dos megaeventos esportivos. Ao aliar os mecanismos de Soft Power com as técnicas de marketing para criar uma marca ("branding”) de uma nação e assim mudar a visão da opinião pública internacional - "nation branding". 310 conceito de "nation branding" também é encontrado em Peter Van Ham, mas com outra denominação. Em artigo na Foreign Affairs, Van Ham escreveu sobre "A ascensão do Estado marca" ("brand state") e diz que "brand state" compreenderia a ideia que o mundo exterior teria a respeito de um país em particular. ${ }^{32}$

Para Van Ham, há marcas que devido à sua imagem e reputação terminam simbolizando seus países no mundo. E, neste sentido, dá como exemplo a BMW e a Mercedes, que simbolizam a eficiência e confiabilidade da Alemanha, ou a Nokia, que era a "embaixadora da Finlândia no mundo". 330 autor acrescenta que em um mundo com excesso de informação, marcas fortes são necessárias para atrair investimentos, bem como para alcançar influência política. Por essa razão, os

\footnotetext{
${ }^{29}$ BRANNAGAN; GIULIANOTTI. Soft Power and Soft Disempowerment: Qatar, Global Sport and Football's 2022 World Cup Finals, 2015; BRANNAGAN; ROOKWOOD. Sports MegaEvents, Soft Power and Soft Disempowerment: International Supporters' Perspectives on Qatar's Acquisition of the 2022 FIFA World Cup Finals, 2016; REICHE. Investing in Sporting Success as a Domestic and Foreign Policy Tool: the Case of Qatar, 2014.

${ }^{30}$ SAMUEL-AZRAN et al. Promoting terror or sport? The Case of Qatar's International Image, 2016.

${ }^{31}$ KRZYZANIAK. The Soft Power Strategy of Soccer Sponsorships, 2016.

${ }^{32}$ VAN HAM. The Rise of the Brand State, 2001.

${ }^{33}$ VAN HAM. The Rise of the Brand State, 2001.
} 
Estados deveriam estar atentos à necessidade de estabelecerem suas marcas, criando uma imagem e uma reputação a nível internacional.

É por isso que Gupta afirma que um dos maiores benefícios de se investir em esportes a nível internacional é a possibilidade de se criar a marca de um Estado, ajudando a estabelecer este nome-marca nacional. ${ }^{34}$ Neste mesmo sentido, Freeman ${ }^{35}$ explica que as nações utilizam esse recurso como forma de construir e gerir suas reputações, acrescenta, ainda, que essa é uma forma de 'diplomacia pública suave', que serve para os Estados não apenas se tornarem atrativos para os estrangeiros como também para os seus cidadãos.

O Catar é, novamente, um bom exemplo de caso de recurso ao 'nation branding' como forma de Soft Power. Primeiro através da Fundação do Qatar e atualmente por intermédio da Qatar Airways (uma empresa estatal, detida em sua integralidade pelo Fundo Soberano do Catar), patrocina o Barcelona, um dos mais emblemáticos clubes do mundo. Em 2011, a Autoridade de Investimento do Catar comprou o Paris Saint-Germain. ${ }^{36} \mathrm{E}$ basta vermos a repercussão internacional da contratação de Neymar, que ocorreu justamente em um período que o Catar sofreu o corte das relações diplomáticas dos vizinhos Arábia Saudita, Emirados Árabes Unidos, Egito e Bahrein.

Fazer da China uma potência do futebol mundial pode ser uma boa maneira de promover a imagem do país. E desde o lançamento do "Plano de desenvolvimento do futebol" investimentos chineses têm sido realizados no intuito de cumprir com tão ambicioso projeto. Como será visto nas próximas seções.

\section{ESTADO E MERCADO}

Mas, como ocorre, efetivamente, a implementação deste plano chinês? A resposta a essa pergunta nos ajuda a compreender, também, porque tantas empresas chinesas se aliaram à FIFA e à mais recente edição de sua maior competição, a Copa do Mundo.

\footnotetext{
${ }^{34}$ GUPTA. The Globalization of Sports, the Rise of Non-Western Nations, and the Impact on International Sporting Events, p. 1786.

${ }^{35}$ FREEMAN. Sport as swaggering: utilizing sport as soft power, 2012.

${ }^{36}$ KRZYZANIAK. The Soft Power Strategy of Soccer Sponsorships, 2016.
} 
O Estado e o mercado são as principais formas de alocação de recursos para as necessidades e os desejos das pessoas. ${ }^{37}$ A China, porém, possui um sistema peculiar. Como argumenta Ostrom, o caso chinês representa um complexo sistema econômico, que requer uma nova teoria que vá além da dicotomia Estado e mercado. ${ }^{38}$ Isso porque as relações entre Estado e mercado no contexto políticoeconômico da China são mais complexas, não sendo possível explicar pela clássica divisão dicotômica. Afinal, desde a reabertura do país para o mundo sob a liderança de Deng Xiaoping, no fim dos anos 1970, a China passou por transformações até a implementação da chamada "economia socialista de mercado", ou "socialismo de mercado" em 1992.39

A partir do "socialismo de mercado", ao deixar de investir diretamente nas empresas estatais, o governo passa a alocar mais verbas em infraestruturas, permitindo o desenvolvimento do ambiente competitivo privado, transformandose num provedor de serviços para que a iniciativa privada prosperasse. ${ }^{40}$ É como se o Estado chinês agisse como um "Estado empreendedor", 41 intervindo no mercado quando necessário, mas tendo como papel primordial a criação das condições para que a iniciativa privada prospere, inclusive através da criação de novos mercados.

Como observa Tan et al., ${ }^{42}$ o governo tende a ser uma espécie de mediação com grupos de interesse, entretanto, no contexto chinês, esses grupos terminam se tornando propagadores das políticas governamentais. Embora o governo e os conglomerados sejam mais interdependentes, o Estado ainda exerce grande poder sobre os recursos e a iniciativa privada precisa manter uma boa relação com o governo se quiser ter acesso a esses recursos.

É o que tem ocorrido na execução do plano do futebol chinês. Para cumprir seus objetivos, o Estado conta com a participação da iniciativa privada. Sem deixar, contudo, de exercer seu controle. Em janeiro de 2017, por exemplo, a

\footnotetext{
${ }^{37}$ LANE; ERSSON. State or Market?: Politics does Matter, 1986.

${ }^{38}$ OSTROM. Beyond Markets and States: Polycentric Governance of Complex Economic Systems, 2010.

${ }^{39}$ CHEN et al. The 2008 Beijing Olympics Opening Ceremony: Visual Insights into China's Soft Power, 2017; GONG; CORTESE. A Socialist Market Economy with Chinese Characteristics, 2017.

${ }^{40} \mathrm{CHEN}$ et al. A Socialist Market Economy with Chinese Characteristics, 2017.

${ }^{41}$ JUNG; EUN; LEE. Exploring Competing Perspectives on Govemment- Driven Entrepreneurial Ecosystems, 2017.

${ }^{42}$ TAN et al. Xi Jin-Ping's World Cup Dreams: From a Major Sports Country to a World Sports Power, 2016.
} 
Administração Geral do Esporte, acusando os clubes de "queimarem dinheiro e pagarem salários muito elevados a jogadores estrangeiros", manifestou sua intenção de limitar os gastos dos clubes profissionais. ${ }^{43}$ Logo a seguir, a Associação Chinesa de Futebol (CFA) mudou o regulamento do limite de jogadores estrangeiros por time. Ao invés da regra de $3+1$ (três estrangeiros mais um asiático) por jogo, passou a apenas três estrangeiros em cada partida (independentemente da nacionalidade), além da obrigação de escalar um chinês sub-23 no 11 titular. Já em maio de 2017, a CFA publicou a implementação de um imposto que recai sobre o valor de transferência de jogadores estrangeiros: $100 \%$ sobre o valor que pagar pelo atleta.

\section{OS INVESTIMENTOS NO FUTEBOL}

Como já foi dito neste artigo, Tan et al. ${ }^{44}$ chamam a atenção para o fato de que embora o governo e os conglomerados privados sejam mais interdependentes, o Estado ainda exerce grande poder sobre os recursos e a iniciativa privada precisa manter uma boa relação com o governo se quiser ter acesso a esses recursos. E isso se faz notar com clareza quando o Estado conclama a iniciativa privada a investir em um determinado setor, como o caso do futebol tem demonstrado.

Desde o lançamento do plano de desenvolvimento do futebol, grandes empresas chinesas como Alibaba, Dalian Wanda Group, Suning Commerce Group e Fosun, para citar apenas alguns exemplos, têm investido tanto no mercado nacional como no exterior. ${ }^{45}$

No caso dos investimentos fora do país, nota-se a busca das empresas chinesas pelo estabelecimento de relações comerciais e troca de conhecimento através do futebol, como propõe o plano de desenvolvimento do futebol, que expressa a necessidade de se "fortalecer a cooperação internacional e a troca de talentos na indústria desportiva", ${ }^{46}$ além de "expandir os canais de relações

\footnotetext{
${ }^{43}$ CHADWICK. A Rap on the Knuckles, but no Burst Bubble, 2017.

${ }^{44}$ TAN et al. Xi Jin-Ping's World Cup Dreams: From a Major Sports Country to a World Sports Power, 2016.

${ }^{45}$ CHADWICK; WIDDOP; PARNEL. A Feast for Wolves, 2017; CHADWICK; WIDDOP; PARNELL. The Guanxi of Football, 2016.

${ }^{46}$ NDRC, 2016, p. 10.
} 
estrangeiras do futebol, encorajando a todos os organismos a organizar variadas formas de atividades internacionais de intercâmbio no futebol". 47

Clubes como os italianos Internazionale de Milão (que pertence ao Suning Group, dono do clube chinês Jiangsu Suning) e Parma, os franceses Nice e Auxerre, os espanhóis Granada, Espanyol e Oviedo e o tcheco Slavia Praga pertencem a empresas, grupos de investimentos ou investidores privados chineses. Por sua vez, destaca-se que Parma e Granada pertencem a Desports Group, empresa sobre a qual voltaremos a falar adiante.

Na Inglaterra, a presença do capital chinês é ainda mais expressivo. 13\% do City Football Group, de propriedade da Abu Dhabi United Group e que controla, dentre outros, o clube inglês Manchester City, foram adquiridos pela China Media Capital. Outro clube inglês de propriedade chinesa é o Wolverhampton Wanderers, que com o dinheiro investido pelo grupo Fosun, conquistou a Championship inglesa em 2017/18 e ascendeu à Premier League.

Além dos Wolves, os outros três grandes clubes da West Midlands inglesa, Birmingham City (Paul Suen Ho Chung da Trillion Trophy Asia), Aston Villa (Tony Xia da Recon Group) e West Bromwich Albion (do investidor Guochuan Lai) estão sob o controle chinês. No Sudeste inglês, o Southampton é atualmente propriedade do empresário chinês Gao Jisheng, dono da Lander Sports Development.

Dono dos Wolves da Inglaterra, o grupo Fosun tem investido em Portugal também. Comprou a maior seguradora portuguesa, a Fidelidade, e uma das empresas mais conhecidas na prestação de serviços de saúde, a Espírito Santo Saúde, hoje Luz Saúde. Tornou-se, ainda, acionista majoritário do maior banco privado português, o Banco Comercial Português (BCP). 0 futebol não ficou de fora dos investimentos da Fosun. Através de sua subsidiária Foyo Culture and Entertainment Co Ltd, tornou-se sócia da empresa portuguesa de agenciamento Gestifute, do agente Jorge Mendes, responsável, dentre outros, pelas carreiras de Cristiano Ronaldo e José Mourinho. ${ }^{48}$ A Foyo também tem acordo com o SL Benfica para exploração comercial e abertura de escolas de futebol na China. E ainda se fala ainda na possibilidade de investirem $€ 10$ milhões no Rio Ave, da I Liga portuguesa.

\footnotetext{
${ }^{47}$ NDRC, 2016, p. 16.

${ }^{48}$ CHADWICK; WIDDOP; PARNELL. The Guanxi of Football, 2016.
} 
O Brasil também já sente os efeitos desta expansão internacional chinesa através do futebol. 0 clube Shandong Luneng é atualmente proprietário do Desportivo Brasil, clube que foi fundado pelo Grupo Traffic. Na busca de cumprir com o objetivo do governo de "fortalecer a cooperação internacional e a troca de talentos na indústria desportiva", 49 o Shandong Luneng leva, a cada ano, 30 jovens jogadores chineses para passarem um ano treinando no Desportivo Brasil. Mais recentemente, tem-se especulado o interesse da empresa chinesa Ledman assumir a gestão de futebol do Nacional-AM. A Ledman já investe no futebol em Portugal, sendo a principal patrocinadora da II Liga, dando, inclusive, nome à competição (naming rights).

No mercado interno chinês, as contratações de jogadores estrangeiros, com valores de transferências muitas vezes bastante inflacionados e salários elevadíssimos, foram o que mais chamaram a atenção. De repente a Super Liga Chinesa passou a estar no centro das atenções do futebol mundial.

Foram precisamente os elevados investimentos em contratações de jogadores estrangeiros, principalmente no mercado europeu, que espantaram o mundo do futebol. De acordo com o relatório da Transfer Matchings Systems/FIFA de 2017, os clubes chineses gastaram US\$168,3 milhões em transferências em 2015, o que representava $10,3 \%$ a mais do que os gatos de todos os outros clubes da Confederação Asiática de Futebol (AFC) juntos. Em 2016, os gastos saltaram para US\$ 451,3 milhões (168,2\% a mais do que no ano anterior), o correspondente a $344,4 \%$ a mais do que todo o restante da Ásia. Com esses números, passou do $20^{\text {o }}$ lugar que ocupava em 2013 no ranking de gastos de transferências para a quinta posição em 2016 (FIFA/TMS, 2017). Somente no mercado de transferências do inverno de 2017 foram gastos 388 milhões de euros (US\$ 411 milhões).

Os clubes chineses, entretanto, não se limitam a concorrer com os europeus apenas nos habituais mercados fornecedores de matéria-prima, como o futebol latino-americano, por exemplo. 0 mercado europeu - e não apenas países periféricos do continente, mas também a maior liga de futebol do planeta, a Premier League inglesa - tem sido um alvo bastante visado pelos chineses. Oscar, Ramires e Graziano Pellè são alguns dos exemplos recentes de jogadores que

${ }^{49}$ NDRC, 2016, p. 10. 
trocaram a liga inglesa pela chinesa, além de Alex Teixeira, que era pretendido pelo Liverpool, mas preferiu se transferir para o Jiangsu Suning, que pagou US\$ 53,5 milhões pelo brasileiro.

O brasileiro Paulinho é outro caso emblemático. Em 2015, trocou o Tottenham da Inglaterra pelo Guangzhou Evergrande. Em 2017, transferiu-se para o Barcelona que pagou 40 milhões de euros pelo jogador. E já em 2018, o titular da Seleção Brasileira na Copa do Mundo 2018 retornou ao Evergrande, por empréstimo, mas com cláusula de compra obrigatória de 50 milhões de euros.

Como bem coloca Gupta, os países não-ocidentais procuram através do dinheiro atrair o talento esportivo de nível mundial, na tentativa de exercerem cada vez mais influência no esporte e assim poderem, também, ditar as regras do esporte. ${ }^{50}$ É o que tem acontecido com a China e sua tentativa de quebrar a lógica eurocêntrica que domina o mercado do futebol internacional, como vimos nos exemplos dos investimentos chineses na esteira das ambiciosas políticas do governo Xi Jinping para o esporte e a indústria esportiva do país.

\section{A China na Copa do Mundo da RúsSia 2018}

A promoção da imagem da China internacionalmente e a busca pela expansão da influência geopolítica do país, uma meta do governo Xi Jinping, podem ser verificadas na forma como a complexa e singular relação Estado-mercado tem se desenrolado na execução do plano de desenvolvimento do futebol.

A Copa do Mundo 2018 na Rússia é um exemplo disso. A seleção chinesa não esteve presente na competição, mas a China não esteve ausente. Wanda, Hisense, Vivo, Mengniu, Yadea, Luci e Diking estavam nos gramados russos, expondo os caracteres do mandarim nas placas de publicidade no entorno dos campos, além de ocuparem espaços nos locais de eventos oficiais da competição.

Por isso, parece-nos relevante observar o que Gupta escreve, ao dizer que os países não-ocidentais - ao trazerem dinheiro para o jogo, uma imensa base de

\footnotetext{
${ }^{50}$ GUPTA. The Globalization of Sports, the Rise of Non-Western Nations, and the Impact on International Sporting Events, p. 1788.
} 
fãs, além de patrocínios e audiência televisiva - vão ser capazes de exercer cada vez mais a condição de determinar onde e como o jogo vai ser jogado. ${ }^{51}$

0 referido autor traz como exemplo para fundamentar seu argumento o caso da transformação do críquete, com a Índia remodelando o Conselho Internacional de Críquete, como consequência dos investimentos bem-sucedidos na Indian Premier League (IPL). A sede do Conselho, por exemplo, saiu de Londres para Dubai e o modelo da IPL passou a ser copiado por outros países. ${ }^{52} 0$ mesmo pode ser aplicado à análise do futebol e da forma como a China tem buscado se tornar influente junto à FIFA o que, consequentemente, implica dizer no futebol mundial.

Com 1,379 bilhão de habitantes, 237 milhões de pessoas que declaram ter o futebol como seu esporte favorito, além de 308 milhões de chineses que dizem assistir, pelo menos, a um jogo de futebol por semana,53 a China reúne uma larga base de fãs e um imenso potencial para audiência televisiva necessárias para os interesses comerciais e de expansão do produto da FIFA, o futebol.

Em 2015, no âmbito de uma investigação do Federal Bureau of Investigation (FBI) dos Estados Unidos, foram expedidos 14 mandados de prisão de membros do alto escalão da FIFA. 0 escândalo de corrupção abalou a entidade máxima do futebol e fez com que muitas multinacionais rescindissem seus contratos com a organização. Foi aproveitando o vácuo deixado pela perda de credibilidade da FIFA que as empresas chinesas passaram a assinar contratos com a entidade, tornandose parceiras do órgão e patrocinadoras de suas competições.

Depois de acumular perdas de US\$ 370 milhões desde o escândalo de corrupção, a FIFA chegou a projetar um faturamento com patrocínios na Copa do Mundo 2018 menor do que aquele registrado em 2014. Inicialmente, a entidade esperava faturar US\$1,45 bilhão este ano, contra US\$1,6 bilhão que havia faturado em 2014. Entretanto, o torneio disputado na Rússia gerou US\$1,65 bilhão de patrocinadores, ${ }^{54}$ ou seja, US\$ 200 milhões a mais do que o esperado e US\$ 50

\footnotetext{
${ }^{51}$ GUPTA. India and the IPL: Cricket's Globalized Empire, 2009a.

${ }^{52}$ GUPTA. India and the IPL: Cricket's Globalized Empire, p. 209.

53 SCHMIDT; SCHREYER; PAFFGEN. Dancing wit the dragon: the quest for the Chinese football consumer, p. 10.

${ }^{54} \mathrm{CHADE}$. Documentos confidenciais apontam para nova receita recorde de $\mathrm{R} \$ 22,7$ bi na Copa, 2018; KPMG. High stakes: The sponsorship and broadcasting value of the FIFA World Cup, 2018.
} 
milhões a mais do que na Copa disputada no Brasil, um ano antes de estourar a bomba que abalou as estruturas da FIFA.

As chinesas Wanda, Hisense, Vivo, Mengniu, Yadea, Luci e Diking foram sete das 19 patrocinadoras da Copa 2018. Juntas, as sete empresas chinesas representam um aporte financeiro de US\$ 835 milhões para a competição da FIFA. Quantia que contribuiu para que o faturamento global da competição atingisse os valores de US\$ 6,12 bilhões e, assim, superasse em US\$ 500 milhões o arrecadado em 2014.

Além da questão financeira em si, é de se destacar como as empresas chinesas estabelecem sua influência junto à FIFA. Na hierarquia dos patrocínios, no mais alto patamar se encontram os "parceiros", no qual está o Wanda Group (de um total de oito empresas). Depois, temos os patrocinadores globais da Copa do Mundo e aí temos Hisense, Vivo e Mengniu - três chinesas em cinco. Por fim, os “apoiadores regionais", categoria criada na Copa de 2014 (e que naquela ocasião contou com seis patrocinadores brasileiros) e que em 2018 teve quatro empresas russas e três chinesas: Yadea, Luci e Diking.

Vale lembrar, ainda, que o Dalian Wanda Group, além de ser um dos "parceiros" da FIFA, também é proprietário da Infront Sports \& Media AG, com sede na Suíça e uma das mais respeitadas companhias de marketing desportivo do mundo. A Infront tem como um dos seus clientes a própria FIFA.

Saindo do âmbito da Copa do Mundo, mas ainda na questão da influência nos bastidores através de patrocínios, ${ }^{55}$ destacamos que o grupo Alibaba, gigante do comércio eletrônico chinês, que pertence ao bilionário Jack Ma, é patrocinador do Mundial de Clubes da FIFA até 2022. Enquanto a Desports, do bilionário Lizhang Jiang e proprietária de Parma e Granada, assinou um acordo com a Confederação Asiática de Futebol (AFC), pouco antes da abertura da Copa do Mundo 2018, para a exploração dos direitos comerciais das competições da entidade. 0 contrato que vai vigorar de 2021 a 2028 tem um valor de US\$ 4 bilhões - sete vezes mais que o anterior.

\footnotetext{
${ }^{55}$ GUPTA. India and the IPL: Cricket's Globalized Empire, 2009a; GUPTA. The Globalization of Sports, the Rise of Non-Western Nations, and the Impact on International Sporting Events, 2009b.
} 
Talvez não seja por acaso que, depois do lançamento do seu plano de desenvolvimento do futebol, a China tenha visto o secretário geral da CFA, Zhang Jian, tornar-se um dos membros do Conselho da FIFA, antigo Comitê Executivo.

\section{CONCLUSÃo}

Nos últimos anos, sob a liderança de Xi Jinping, a China tem exortado o "Sonho Chinês” (中國夢) ${ }^{56}$ como parte da ambição do atual presidente de "rejuvenescimento", que passa pela modernização do país e o sucesso econômico. ${ }^{57}$ Em outubro de 2017, o XIX Congresso do Partido Comunista Chinês incluiu a teoria da “Nova era do socialismo com características chinesas” (新时代中国特色社会主义), de Xi Jinping, na Constituição do país. ${ }^{58}$

A ideia de "rejuvenescimento" passa, também, pela ascensão da China como protagonista e líder global. 0 esporte não ficou de fora dos planos de desenvolvimento econômico e expansão da influência chinesa. Em 2014, o Conselho de Estado publicou as “Opiniões para a aceleração do desenvolvimento da indústria desportiva e promover o consumo do esporte” (国务院䏌于加快发展体育产业促进体育消费的若干意见), um projeto que visa transformar o país em uma potência da indústria esportiva mundial.

O futebol é sua mola propulsora. Para isso, foi lançado o "Plano de desenvolvimento do futebol a médio e longo prazo (2016-2050)" (中国足球中长期发展规划 [2016-2050年]), que diz “ser de grande importância no que toca à construção de uma nação esportiva poderosa, a promoção do desenvolvimento econômico e social, e a realização do Sonho Chinês, o rejuvenescimento da nação chinesa". ${ }^{9}$

A busca pelo protagonismo global no esporte também é evidenciado no plano do futebol, que assinala a importância de "fortalecer a cooperação

\footnotetext{
${ }^{56}$ PETERS. The Chinese Dream : Xi Jinping Thought on Socialism with Chinese Characteristics for a New Era, p. 1301.

${ }^{57}$ PETERS. The Chinese Dream : Xi Jinping Thought on Socialism with Chinese Characteristics for a New Era, p. 1302.

${ }^{58}$ PETERS. The Chinese Dream : Xi Jinping Thought on Socialism with Chinese Characteristics for a New Era, p. 1299.

${ }^{59}$ NDRC, 2016, p. 1.
} 
internacional",60 além de "expandir os canais de relações estrangeiras do futebol". ${ }^{61} \mathrm{E}$, para isso, o Estado chinês conta com a participação da iniciativa privada que, como demonstramos neste artigo, tem feito volumosos investimentos no futebol, tanto no mercado interno quanto no mercado internacional.

Como colocam Scutti e Wendt (2016), o futebol, ao lado da demografia, desenvolvimento tecnológico, econômico e poderio militar, é um critério de avaliação de poder internacional. Assim sendo, argumentam os autores que "geopolítica e futebol se tornaram universos inseparáveis". 62 A geopolítica do futebol mundial está em transformação. Países emergentes, como o Brasil, a Rússia ou o Catar, perceberam no esporte, e mais especificamente no futebol, um instrumento de Soft Power capaz de os reposicionar no contexto internacional. A China tem sido uma das forças motrizes desta mudança.

A seleção chinesa não disputou a Copa do Mundo da Rússia, mas a China esteve presente no Mundial da FIFA. A Vice-Premiê chinesa, Sun Chunlan, foi à cerimônia de abertura em Moscou e se encontrou com o presidente russo, Vladimir Putin - "estes eventos atraem políticos de todo o mundo, particularmente nas cerimônias de abertura". ${ }^{63}$ Além disso, sete empresas chinesas patrocinaram a competição, injetando US\$ 835 milhões nos cofres da FIFA.

Um dos objetivos da China é sediar uma Copa do Mundo. Com a influência financeira exercida pelos patrocínios de empresas chinesas e a consequente influência política junto à entidade máxima do futebol, ${ }^{4}$ parece-nos que o "Reino do Meio" vai consolidando sua posição na geopolítica do esporte mais popular do planeta, fazendo crer que, em se mantendo estes investimentos, a Copa do Mundo na China venha a ser apenas uma questão de tempo. Por isso, entendemos que o contributo deste artigo se encontra exatamente no fato de analisar não apenas a estratégia chinesa para o futebol sob uma perspectiva diferente, mas também de

\footnotetext{
60 NDRC, 2016, p. 10.

${ }^{61}$ NDRC, 2016, p. 16.

62 SCUTTI; WENDT. Football and Geopolitics, p. 105.

63 GIULIANOTTI. The Beijing 2008 Olympics: Examining the Interrelations of China, Globalization, and Soft Power, 2015.

${ }^{64}$ GUPTA. India and the IPL: Cricket's Globalized Empire, 2009a; GUPTA. The Globalization of Sports, the Rise of Non-Western Nations, and the Impact on International Sporting Events, 2009b.
} 
refletir a esfera política do futebol, suas conexões com a geopolítica internacional e interesses econômicos e de que forma o plano chinês tem influenciado este universo futebolístico.

\section{REFERÊNCIAS}

ALMEIDA, Bárbara Shaustek De; MARCHI JÚNIOR, Wanderley; PIKE, Elizabeth. The 2016 Olympic and Paralympic Games and Brazil's Soft Power. Contemporary Social Science, v. 9, n. 2, p. 271-283, 2013.

BRANNAGAN, Paul Michael; GIULIANOTTI, Richard. Soft Power and Soft Disempowerment: Qatar, Global Sport and Football's 2022 World Cup Finals. Leisure Studies, v. 34, n. 6, p. 703-719, 2015.

BRANNAGAN, Paul Michael; ROOKWOOD, Joel. Sports Mega-Events, Soft Power and Soft Disempowerment: International Supporters' Perspectives on Qatar's Acquisition of the 2022 FIFA World Cup Finals. International Journal of Sport Policy, v. 8, n. 2, p. 1-16, 2016.

CHADE, Jamil. Documentos confidenciais apontam para nova receita recorde de $R \$$ 22,7 bi na Copa. Disponível em: <https://bit.ly/2QgxfxD>. Acesso em: 9 jun. 2018.

CHADWICK, Simon. A Rap on the Knuckles, but no Burst Bubble. Disponível em: <https://bit.ly/2iMyMua>. Acesso em: 28 set. 2018.

CHADWICK, Simon; WIDDOP, Paul; PARNEL, Daniel. A Feast for Wolves. Disponível em: <https://bit.ly/2iEWz2K>. Acesso em: 28 set. 2018.

CHADWICK, Simon; WIDDOP, Paul; PARNELL, Daniel. The Guanxi of Football. Disponível em: <https://bit.ly/2hpk1Sa>. Acesso em: 28 set. 2018.

CHARI, Tendai. Discursive Constructions of the Germany-Brazil Semi-Final Match During the Fifa 2014 World Cup: the Limits of Football As a Soft Power Resource. Communicatio-South African Journal for Communication Theory and Research, v. 41, n. 4, p. 405-422, 2015.

CHEN, Chwen Chwen; COLAPINTO, Cinzia; LUO, Qing. The 2008 Beijing Olympics Opening Ceremony: Visual Insights into China's Soft Power. Visual Studies, v. 27, n. 2, p. 188-195, 2012.

CHEN, Xiaodong. et al. Who Provides the Capital for Chinese Growth: the Public or the Private Sector? Applied Economics, v. 49, n. 23, p. 2238-2252, 2017.

CHINA'S NATIONAL DEVELOPMENT AND REFORM COMMISSION. Medium and Long-Term Plan of Chinese Football Development. [s.I: s.n.]. 
CORNELISSEN, Scarlett. The Geopolitics of Global Aspiration: Sport MegaEvents and Emerging Powers. The International Journal of the History of Sport, v. 27, n. 16-18, p. 3008-3025, 2010.

DELGADO, Daniel Ricardo Lemos. Opening Ceremonies of International Sports Events: The Other Face of Chinese Soft Power. The International Journal of the History of Sport, v. 33, n. 5, p. 1-17, 2016.

FIFA. FIFA Men's World Ranking. Disponível em: <https://bit.ly/2kYDW9T>. Acesso em: 28 set. 2018.

FIFA/TMS. Global Transfer Market Report 2017. [s.I: s.n.].

FREEMAN, Kevin. Sport as Swaggering: Utilizing Sport as Soft Power. Sport in Society, v. 15, n. 9, p. 1260-1274, 2012.

GIULIANOTTI, Richard. The Beijing 2008 Olympics: Examining the Interrelations of China, Globalization, and Soft Power. European Review, v. 23, n. 2, p. 286-296, 2015.

GONG, Xun; CORTESE, Corinne. A Socialist Market Economy with Chinese Characteristics: The Accounting Annual Report of China Mobile. Accounting Forum, v. 1978, n. August 2016, p. 1-15, 2017.

GRIX, Jonathan; LEE, Donna. Soft Power, Sports Mega-Events and Emerging States: The Lure of the Politics of Attraction. Global Society, v. 27, n. 4, p. 3741, 2013.

GUPTA, Amit. India and the IPL: Cricket's Globalized Empire. The Round Table, v. 98, n. 401, p. 201-2011, 2009a.

GUPTA, Amit. The Globalization of Sports, the Rise of Non-Western Nations, and the Impact on International Sporting Events. The International Journal of the History of Sport, v. 26, n. 12, p. 1779-1790, 2009b.

HONG, Fan.; ZHOUXIANG, Lu. Sports and Politics in the 1980s: The Olympic Strategy. The International Journal of the History of Sport, v. 29, n. 1, p. 7497, 2012a.

HONG, Fan; ZHOUXIANG, Lu. From Barcelona to Athens (1992-2004): "Juguo Tizhi" and China's quest for global power and Olympic glory. The International Journal of the History of Sport, v. 29, n. 1, p. 113-131, 2012b.

HONG, Fan; ZHOUXIANG, Lu. Representing the New China and the Sovietisation of Chinese Sport (1949-1962). International Journal of the History of Sport, v. 29, n. 1, p. 1-29, 2012c.

HONG, Fan; ZHOUXIANG, Lu. Sport in the Great Proletarian Cultural Revolution (1966-1976). International Journal of the History of Sport, v. 29, n. 1, p. 53-73, 2012d.

HONG, Fan; ZHOUXIANG, Lu. China, the Asian Games and Asian Politics (19742006). International Journal of the History of Sport, v. 29, n. 1, p. 98-112, 2012e.

HONG, Fan.; ZHOUXIANG, Lu. China's Sports Policy and Politics in the PostBeijing Olympics Era. International Journal of the History of Sport, v. 29, n. 1, p. 184-189, $2012 f$. 
HONG, Fan; ZHOUXIANG, Lu. The Professionalisation and Commercialisation of Football in China (1993-2013). The International Journal of the History of Sport, v. 30, n. 14, p. 1637-1654, 2013.

JUNG, Kwangho; EUN, Jong-Hwan; LEE, Seung-Hee. Exploring Competing Perspectives on Government- Driven Entrepreneurial Ecosystems: Lessons from Centres for Creative Economy and Innovation (CCEI) of South Korea. Centres for Creative Economy and Innovation (CCEI) of South Korea, European Planning Studies, v. 25, n. 5, p. 827-847, 2017.

KORNEEVA, Vera A.; OGURTSOV, Evgeny S. The Politicization of Sports as a Soft Power Public Resource. Indian Journal of Science and Technology, v. 9, n. 29, 2016.

KPMG. High stakes: The sponsorship and broadcasting value of the FIFA World Cup. Disponível em: <https://bit.ly/2xZsW1Y>. Acesso em: 09 jul. 2018.

KRZYZANIAK, John S. The Soft Power Strategy of Soccer Sponsorships. Soccer \& Society, v. 970, n. January, p. 0, 2016.

LANE, Jan-Erik; ERSSON, Svante. State or Market?: Politics does Matter. International Political Science Review, v. 7, n. 1, p. 91-104, 1986.

LIU, Dongfeng. The Sports Industry: the Next Big Thing in China? China Policy Analysis, 2017.

MANGAN, J. A.; OK, Gwang; KWAK, Young Man. East Reflects on West, East Meets West!: South Korean Media Responses to London 2012. The International Journal of the History of Sport. Taylor \& Francis, 2013. Disponível em: <https://bit.ly/2QgWwHN> Acesso em: 28 set. 2018.

NIELSEN SPORTS. China and Football. [s.l: s.n.].

NYE, Joseph Samuel. Soft Power: The Means to Success in World Politics. 1. ed. New York: PublicAffairs, 2004.

NYE, Joseph Samuel. China and Soft Power. South African Journal of International Affairs, v. 19, n. 2, p. 151-155, 2012.

OSTROM, Elinor. Beyond Markets and States: Polycentric Governance of Complex Economic Systems. The American Economic Review, v. 100, n. June, p. 1-33, 2010.

PEOPLE'S DAILY. China to Build 50,000 Football Schools by 2025. Disponível em: <https://bit.ly/2IJTGzr>. Acesso em: 3 mar. 2017.

PETERS, Michael. A. The Chinese Dream: Xi Jinping Thought on Socialism with Chinese Characteristics for a New Era. Educational Philosophy and Theory, v. 49, n. 14, p. 1299-1304, 2017.

PLUNKETT RESEARCH. Plunkett Research Sports Industry. Disponível em: <https://bit.ly/2DOr7LR>. Acesso em: 28 mar. 2018.

REICHE, Danyel. Investing in Sporting Success as a Domestic and Foreign Policy Tool: the Case of Qatar. International Journal of Sport Policy and Politics, v. 6940, n. April 2015, p. 1-16, 2014. 
ROTH, Andrew. World Cup Plaudits Cheer Putin as Russia Revels in Spotlight. Disponível em: <https://bit.ly/2xlHbcb>. Acesso em: 10 jul. 2018.

SAMUEL-AZRAN, Tal; et al. Promoting terror or sport? The Case of Qatar's International Image. American Behavioral Scientist, v. 60, n. 9, p. 1101-1115, 2016. SCHMIDT, Sascha L.; SCHREYER, D.; PAFFGEN, C. Dancing wit the dragon: the quest for the Chinese football consumer. [s.l: s.n.].

SCUTTI, Giuseppe; WENDT, Jan A. Football and Geopolitics. GeoSport for Society, v. 5, n. 2, p. 100-106, 2016.

TAN, Tien-Chin; et al. Xi Jin-Ping's World Cup Dreams: From a Major Sports Country to a World Sports Power. The International Journal of the History of Sport, v. 3367, n. November, p. 1-17, 2016.

VAN HAM, Peter. The Rise of the Brand State. Disponível em: $<$ https://fam.ag/2QeMyXC>. Acesso em: 10 jul. 2018.

ZHAN, Xinhuan. The History and Development Trend of China's Sports Industry Policy. p. 400-402, 2013. 